Article

\title{
Treatment, Palliative Care or Euthanasia? Comparing End of Life Issues in Veterinary and Human Medicine
}

\author{
Ruth E. Eyre-Pugh ${ }^{1, *}$ and James W. Yeates ${ }^{2}$ \\ ${ }^{1}$ Independent Researcher. Jordans Farm, Lower Green, Wakes Colne, Colchester, Essex, CO6 2AZ, UK. \\ ${ }^{2} \mathrm{CVO}$, Royal Society for the Prevention of Cruelty to Animals (RSPCA), UK; james.yeates@rspca.org.uk \\ ${ }^{*}$ Correspondence: rutheyre.pugh@gmail.com ; Tel.: +44-790-332-0631
}

\begin{abstract}
This is the second of a series of two papers comparing the end of life issues in human and veterinary medicine. We outline the main differences between human and animal patients such as patient communication, finance and 'conflicts of interest' between animal, owner and veterinarian. We discuss striking similarities between human and veterinary issues such as assessing quality of life and the primary role of the attending veterinarian or doctor being the welfare and care of the patient. This paper takes the form of an ethical argument in favour of allowing euthanasia in human medicine, by providing insights into end of life issues for humans from an independent veterinary perspective. Veterinary surgeons are well trained in the ethics of euthanasia and put it to good use in the best interest of their animal patients. Doctors in the UK are limited and unwilling to put forward a case for the option of euthanasia for those patients who face a slow and agonizing death. With advances in medical science being able to significantly prolong the dying process, autonomy for the patient demands a review of the law regarding patient choice in the UK.
\end{abstract}

Keywords: euthanasia; veterinary ethics; medical ethics; end-of-life; assisted suicide; palliative care; assisted dying; moral stress.

\section{Introduction}

A retired surgeon from Australia who has been giving lectures and running workshops on end of life issues for the last 20 years, believes that the space between being ready to die and actually dying is a time of great suffering [1] (p. 118). Indeed, one of the key findings of the legal and social issues committee of the Victoria Parliament in their inquiry into end of life choices, was that 'Prohibition of assisted dying is causing some people great pain and suffering. It is also leading some to end their lives prematurely and in distressing ways' [2] (p. xx).

In a climate of enhanced patient autonomy, patients wish to retain control of their lives until they die. Medical practitioners are increasingly likely to encounter patients seeking assisted dying [3].

The aim of this article is to assess whether human medicine should join veterinary medicine by including euthanasia as a legal end of life option. As euthanasia is wanted by the majority of the UK public [4], but resisted by the medical profession [5] and the Government [6], can the experiences and values in veterinary medicine help sway the Government to change the law in the UK for the benefit of human patients so they can be assisted to die at a time of their choosing?

PICO Question. Should human medicine follow veterinary medicine by including euthanasia or medically assisted suicide as a legal end of life option in the UK? 
The main conclusion of this paper is that euthanasia of the terminal patient is a humane option if ending the life of the patient will prevent additional suffering and unnecessary pain and therefore should be included as a legal end of life option in the UK.

\section{The evidence}

The source of the evidence for this paper is documented in a Review, as yet unpublished [7].

\section{Discussion}

\subsection{Exclusions}

A discussion about the justification for destroying healthy animals to control stray animal populations or for Notifiable Disease Control purposes or for aggressive/dangerous dog control, does not come under the remit of this debate.

Nor does ethical dilemmas about turning off life supporting treatments in Intensive Care Units as this situation is not encountered in veterinary medicine and is already adequately dealt with within the law.

\subsection{Comparing end of life issues in veterinary and human medicine}

\subsection{1.}

Is this a valid and fair comparison?

There are many who would dismiss the comparison of human and animal end of life issues as being irrelevant [8]. This is perfectly understandable if they have never valued the life and love of an animal and witnessed the suffering of a loved one. Whereas those who have had both experiences can testify that there is much to be learnt from the comparison.

Bachelard has written a paper putting forward the philosophical argument that it is wrong to draw conclusions about euthanasia in humans by comparing it to the relief of suffering of animals. She argues that by putting humans out of their agonizing suffering we would be reducing Homo sapiens to the level of an animal. Although she agrees that we have evolved from animals, she argues that it is the development of a fellowship society with moral values that makes us distinct. The doctor looking at his/her patient recognizes that the patient shares the same properties as him/herself with the same significance and human fate. Yet she states that 'since there is no empirically relevant difference between human beings and animals in terms of our capacity for suffering, then there can be no warrant for differential treatment of like cases as long as those involved freely consent to the act of euthanasia' [9] (p.136). 'How does this discussion connect to the agonizing physical and mental suffering that is at issue in the argument from mercy?' She argues that the analogy between humans and animals obscures the fact that most human suffering is an aspect of the human condition to which we may respond in varying ways, with varying degrees of lucidity, depth, honesty and courage. She agrees that there will certainly be many cases, in which no third party, no non-sufferer, has the right to expect the sufferer to respond deeply to the suffering, to be adequate to their suffering, to make anything of it in their lives. 'The recognition that theirs is a human misfortune, a human tragedy, must condition what it is that we do to them' [9] (p. 138).

She concludes by saying, 'there remains the possibility of merciful killing which does not demean the individual for whose sake it is done. Euthanasia then may be done in a spirit alive to the sense of the depth and meaning of this life and its suffering.' Human beings are individuals in possession of 
inner lives capable of ever deepening responsiveness to one another and to the human condition [9] (pp. 138-139).

\subsection{2.}

The major differences between veterinary and human medicine, when comparing end of life issues, are that:

1. Animals cannot talk nor prepare an 'advance directive', however vets are trained how to assess their condition and needs.

'An "advance directive" enables competent individuals to design and document their health care decision plan in advance in case of future disability or terminal illness' [10].

2. Financial concerns may come into the equation more for animal treatments. Although in cases of futile treatments, healthcare providers also have to consider the allocation of limited resources available to manage the case scenario so as to avoid inequity [10]. 'They have to address the issues of unnecessary and unequal distribution of resources by withdrawing or withholding futile treatment' $[11,10]$.

3. Human medicine has become less 'paternalistic' and more towards 'autonomous decision making'. 'The healthcare professional should respect the patient's autonomy while considering its [legal] limitation and carry out their duties to benefit the patient without doing harm. The physician has a duty to preserve a patient's life but this duty is not to be confused with unnecessary use of resources and inflicting more harm than good to the patient by continuing medically futile treatments' [11,10]. 'Communication between patient and families, discussing the patient's goal regarding treatment and care, can be helpful to bridge a gap between the patient, their families and the physician' [12]. In veterinary medicine concerns about autonomy and informed consent include considerations about the veterinarian's obligations to the animal versus the client and issues arising from veterinary and client differences in assessing animal welfare [13].

4. Thus 'the status of animals as the property of their owners makes veterinary medicine fraught with competing interests, and these "conflicts of interests" generate difficult ethical quandaries for clinicians. For example even if it were possible to accurately determine the best interest of the horse in a particular case of laminitis, it is unlikely that this factor would be the only one in making a treatment decision. Veterinary medicine rarely has the luxury of focusing solely on the well-being of the animal. It is a branch of medical practice that has conflict of interest issues embedded in its very structure, with clinicians having dual (and often conflicting) loyalties to both patients and clients' [14] (p.106). I personally would like to hypothesize that it is this 'conflict of interests,' added to the stress and anxiety associated with providing an out-of-hours service at all hours of the day and night, which is behind the extraordinarily high rate of suicide amongst practicing veterinarians.

Platt et al. $[15,16]$, did a systematic review of the prevalence of suicide in veterinary surgeons and concluded that the risk was at least three times that of the general population in the UK and the risk is also elevated in some other countries. Access to methods, including weapons and pharmaceutical agents is a common factor in deaths of veterinarians. The possibility that familiarity with convenience animal euthanasia may increase the likelihood of suicide is disputed by Ogden et al. [17]. They conducted a survey of preclinical and clinical veterinary 
students and recent graduates, looking for a relationship between attitudes to convenience animal euthanasia and human euthanasia or suicide, and found none.

5. For humans 'fear of death has a primary role of physical self-preservation.' 'To permit normal psychological functioning, denial/repression puts the fear of death on a back burner.' [18] (p. 224). 'A man will say, of course, that he knows that he will die someday, but that he does not really care. He is having a good time living, and he does not think about death and does not care to bother about it - but this is a purely intellectual, verbal admission. The effect of fear is repressed' [19,18]. This 'denial of death certainly decreases with age' [18]. Animals do not seem to have an innate fear of dying. Veterinarians believe that prior to euthanasia they do not sense nor fear imminent death. Whereas humans are aware of their mortality and this selfawareness elicits crippling existential anxiety [20]. Many humans are afraid of death, both of the unknown and of the actual dying process. It is this fear of the dying process that can be relieved by euthanasia as their fears of any accompanying pain, or distress due to choking and suffocation, can be dissipated by a controlled death.

6. Some human cultures have strong views about euthanasia and end of life choices, for example, the idea that brain death in Islamic law does not constitute the end of life as the soul is still present in the body, forbids the use of euthanasia [21]. Jehovah's Witnesses are allowed to forego life sustaining blood transfusions as they believe this will give them a better chance of enjoying eternal paradise. We respect these patients' autonomy [1]. Catholic moral theology views euthanasia and physician assisted suicide as a direct negation of the precious gift of human life [22].

Animals are not religious and do not share these beliefs.

\subsection{3.}

There are striking similarities between end of life issues in veterinary and human medicine. These include: making the decision, refusing treatments, quality of life, loss of dignity, the guilt, the welfare and care of the patient, ethical challenges, moral stress and cognitive dysfunction syndrome.

1. Veterinarians encounter the problem of making the decision to end an animal's life when the desires of the human guardian are often difficult to identify [23,24]. Likewise in human medicine when the patient is incapacitated often the primary carers are very bad at making end of life decisions [10], so it is up to the doctor to guide the way. Pochard et al. concluded that more than two-thirds of family members visiting patients in intensive care units suffer from symptoms of anxiety or depression which could affect their decision-making capacity, therefore involvement of anxious or depressed family members in end-of-life decisions should be carefully discussed [25].

In modern day veterinary practise, owners vary from those being totally reliant on the veterinarians' advice, through to increasingly, those who are used to making their own decisions based on best information available [13]. Human equipment for decision-making stems from multiple levels of consciousness: intuitive, driven by subconscious processes; gut level, driven by adrenal hormones; cognitive and uniquely rational; and cognitive but socially influenced in complex ways, [26]. Situations where owners found decision-making more difficult were: the lack of a clear cut-off point in cases with slow deterioration, or fluctuating levels of health. Other conflicts arose when humans identified with the dog's condition [13]. 
Here euthanasia could be postponed as it raised complex questions, too tough to deal with, about human patients in similar situations. An example:

"My husband was ill and he found it very difficult that we should part with the dog, because he thought, well, now she is ill and old and then you just get rid of her, and maybe he felt it was a bit like that with him too," (owner of euthanized old dog with dementia).

Finally, conflicts sometimes arose between family members who disagreed over the choice of treatment or about the timing of euthanasia [13].

2. The guilt human guardians feel about their power of life and death over their beloved animal companion [27], means that taking responsibility for ending the animal's life and the feeling of being an executioner are hard for some owners to bear. Although acknowledging that decisions about euthanasia were their responsibility, making this decision sometimes felt wrong and made the owner feel like a bad person for taking a life. Although the one situation they probably feared the most was one in which they had let their pet suffer [13]. This guilt also extends to the vet performing the euthanasia and other carers [28].

This is something which would need to be addressed to support family members and health professionals involved in end of life decision making of dying humans, were euthanasia to be introduced as an option. However, personal autonomy must be respected, Landry et al. ask: 'Does respect for patient autonomy also require that patients have choices concerning the method of assistance in death, or euthanasia? In other words, will the method of PAD be strictly regulated, or negotiated between physician and patient?' [29] (Section 4.1). I personally would like the patient to have a choice between either ingesting a bitter, foul tasting medicine as their last ever drink or being able to say or indicate - 'I'm ready' seconds before feeling drowsy and losing consciousness.

3. An animal patient 'refusing treatments' is frequently encountered in veterinary medicine and surgery, to the extent that some medications need to be administered by the vet or owner, as being in the best interests of the animal. It is however the similarities between the owner of the animal and the human patient refusing treatments whish enters into this discussion. The emotional bond between the client and the animal patient may be so strong, and the immediate situation so confusing, that a client may be unable or unwilling to critically appreciate the prolonged suffering a treatment modality might produce. It is the responsibility of the veterinarian to guard against the owner wishing to continue with treatments, at the expense of the patient's quality of life. The existence and availability of a therapeutic or diagnostic modality is not an ethical argument for its use [30]. In human medicine often close family members feel the same way but more often than not it is the patient who refuses the treatment, very often accompanied by the refusal of food and water. This frequently occurs near the end of life when the patient who wishes to depart this life has no other option.

4. Quality of life. In order to assess quality of life Nieburg and Fischer suggest asking the human guardian whether the animal can do the things that he or she once enjoyed; whether there is more pain or more pleasure in his or her life; whether the animal has become bad-tempered and snappish as a result of old age or illness; whether the animal has lost control of his or her bodily functions [31,24]. 
Folger et al. state that 'the veterinarian must make every effort to assist the patient to enjoy the Five Freedoms:

\section{FREEDOM FROM HUNGER AND THIRST. FREEDOM FROM DISCOMFORT. FREEDOM FROM PAIN, INJURY OR DISEASE. FREEDOM TO EXPRESS NORMAL BEHAVIOR. FREEDOM FROM FEAR AND DISTRESS.}

Quality of life considerations should remain a continuous dialogue between the veterinarian and the client' [30].

Vets are constantly monitoring the quality of life of their patients and trying not to neglect any animal, this includes captive animals in zoos. In an article about quality of life in geriatric zoo animals, Follmi et al. discovered that many geriatric captive animals outlive their life expectancy in the wild and as a result suffer from many conditions mainly related to the musculoskeletal system and neoplasia, and despite the best treatments available, this compromises their quality of life and welfare. They have developed a comprehensive scoring system for the different species of animals found in zoos, to help veterinarians arrive at informed decisions regarding the best time for euthanasia to prevent further suffering [32].

In human medicine how can quality of life be maintained whilst under deep palliative sedation? Are the doctors and physicians merely maintaining quality of death? They are not shortening life, as concluded by Maltoni et al. in a systematic review, 'palliative sedation, when appropriately indicated and correctly used to relieve unbearable suffering, does not seem to have any detrimental effect on survival of patients with terminal cancer' [33] (p. 1378). 'Median survival (survival was defined as the number of days from hospice/hospital admission or from the start of home care to death) of sedated and non-sedated patients varied from 7 to 36.5 days and from 4 to 39.5 days, respectively; this was not statistically different between the two patient groups' (p. 1379). 'Palliative sedation can therefore be considered as an integral part of the palliative medicine approach to end-of-life care' [33] (p. 1382).

However, Beller et al. found that evidence is lacking on the success of controlling symptoms adequately with palliative sedation and 'No studies measured the primary outcome of this review, quality of life or well-being, in a formal way. Many of the study reports discussed the "settling" of symptoms in an anecdotal way; however, there were no quantitative reports' [34] (p. 15). 'Terminally ill people experience a variety of symptoms in the last hours and days of life, including delirium, agitation, anxiety, terminal restlessness, dyspnoea, pain, vomiting, and psychological and physical distress. In the terminal phase of life, these symptoms may become refractory, and unable to be controlled by supportive and palliative therapies specifically targeted to these symptoms. Palliative sedation therapy is one potential solution to providing relief from these refractory symptoms' [34] (p. 3). However, 'The results demonstrated that despite sedation, delirium and dyspnoea were still troublesome symptoms in these people in 
the last few days of life. Control of other symptoms appeared to be similar in sedated and nonsedated people' [34] (p. 4).

In a recent study from France, health care providers found that in many cases midazolam failed to provide relief from some refractory symptoms. Also deep sedation broke down the patient/carer relationship [35].

UK doctors are monitoring and treating pain and symptom management under the umbrella of palliative care but in most cases are failing to assess quality of life as they have no armoury to do anything about it when it becomes unacceptable to the patient.

4 Suffering can be both physical and emotional for man and beast. Even animals appear to be aware of 'loss of dignity,' for example, when they are unable to fulfil normal toileting behaviour which is both instinctive and instilled into them from training in their early days. Also, existential suffering in humans is not relieved by the treatment of physical symptoms alone. Loss of dignity and a feeling that they have outlived their time, can cause existential suffering that is unremitting and of such depth that more often than not the patient is sedated.

5 To compare the similarities in the ethics involved in end of life issues between veterinary and human care at the end of life in the UK, it is useful to compare the Veterinary Oath taken when becoming a member of the Royal College of Veterinary Surgeons in order to practise, and the General Medical Council's guidance on the duties of a good doctor, the closest thing to a modern Hippocratic Oath, under the title 'Good Medical Practice' [36].

\section{The welfare of the patient}

It is the ethical and moral responsibility of every veterinarian to advocate the welfare of the patient. This is the veterinarian's primary responsibility [30].

On admission to membership of the RCVS, and in exchange for the right to practise veterinary surgery in the UK, every veterinary surgeon makes a declaration, which, since 1st April 2012, has been:

"I PROMISE AND SOLEMNLY DECLARE that I will pursue the work of my profession with integrity and accept my responsibilities to the public, my clients, the profession and the Royal College of Veterinary Surgeons, and that, ABOVE ALL, my constant endeavour will be to ensure the health and welfare of animals committed to my care" [37] (p. 14).

\section{The care of the patient}

Here are the duties of a doctor, registered with the General Medical Council, relevant to end of life care:

'Make the care of your patient your first concern. Take prompt action if you think that patient safety, dignity or comfort is being compromised. Work in partnership with patients: Listen to, and respond to, their concerns and preferences. Respect patients' right to reach decisions with you about their treatment and care' [36].

A small study, done in 2001, of doctors reflecting on how they learnt to truly care for dying patients in New Zealand, revealed that their training had been inadequate in preparing them for such care [38]. 
6 Ethical challenges about end of life issues and dealing with requests for euthanasia in particular, are confronting both doctors and veterinarians on a daily basis. If a client requests that a veterinarian should euthanize a healthy animal, the vet can refuse, despite the owner being within his or her legal rights to make such a request.

In a national survey, carried out by Meier et al. of physician-assisted suicide and euthanasia in the United States, prior to any legalization, the 81 respondents (weighted proportion 6.4\%) who reported having acceded to at least one request for assistance with suicide or a lethal injection were asked to describe the most recent case. $47 \%$ of these respondents wrote a prescription for the purpose of hastening death, and 53\% administered a lethal injection. The perceived reasons for the request were: discomfort other than pain (reported by $79 \%$ of the respondents), loss of dignity (53\%), fear of uncontrollable symptoms (52\%), actual pain (50\%), lost meaning in their lives (47\%), being a burden (34\%), and dependency $(30 \%)$. The reasons given for acceding to the request were: severe discomfort other than pain (reported by $78 \%$ of the respondents), refractory symptoms (72\%), a life expectancy of less than six months (69\%), and severe pain (29\%) [39].

\section{Moral Stress}

Rollin states that 'Euthanasia is a double-edged sword in veterinary medicine. It is a powerful and ultimately the most powerful tool for ending pain and suffering. Demand for its use for client convenience is morally reprehensible and creates major moral stress for ethically conscious practitioners. But equally reprehensible and stressful to veterinarians is the failure to use it when an animal faces only misery, pain, distress, and suffering. A recent study published in England confirms that suicide among veterinarians is higher than in any other profession. In the 1980s, I identified a problem that is pervasive among humane society and animal shelter workers, laboratory animal personnel and veterinarians and called it "moral stress," which is a unique and insidious form of stress that cannot be alleviated by normal approaches to stress management. It arises among people whose life work is aimed at promoting the well-being of animals, yet in far too many cases, their major activity turns out to be killing unwanted dogs and cats. Most veterinarians enter the field to treat disease, alleviate pain and suffering, and provide high-quality of life for the animals to whom they minister. Yet historically, veterinarians, like humane society workers, have been called upon to kill unwanted animals. This state of affairs creates moral stress which grows out of the radical conflict between one's reasons for entering the field of animal work, and what one in fact ends up doing' [40] (p. 651).

It begs the question: Is the BMA more interested in protecting its members from moral stress than relieving the suffering of patients and their loved ones? 'BMA policy insists that if euthanasia were legalised there should be a clear demarcation between those doctors who would be involved in it and those who would not' [41]. It is ironic that one of the key reasons given for why current BMA policy firmly opposes assisted dying is that in their view, permitting assisted dying 'would be contrary to the ethics of clinical practice, as the principal purpose of medicine is to improve patients' quality of life, not to foreshorten it'. In my view the arguments for their other key reasons for opposing assisted dying are equally weak. 
Pain management: failure to acknowledge, recognize and control pain in the patient is unethical, and significantly impairs the quality of life of the patient [30].

8 Cognitive dysfunction syndrome is a recognized syndrome in old cats and dogs, with similar brain pathology to that found in humans with dementia and Alzheimer's disease [42]. Luckily it rarely reaches the stages found in human medicine.

'Difficulty chewing and swallowing are almost universal and expected complications of progressive dementia. Swallowing problems often lead to aspiration events and pneumonia which usually causes considerable discomfort, clinicians should pay attention to symptom controls. Benzodiazepines or antipsychotics may be necessary to reduce fear and agitation in patients with dementia in the terminal phase. Opioids are the main symptomatic treatment of dyspnea. Changes in a dying patient's breathing pattern might be indicative of considerable neurologic compromise. A study of predictors of survival among 178 Dutch nursing home patients with dementia who had artificial nutrition and hydration withdrawn or withheld showed that $59 \%$ of patients died within 1 week. This may be slightly extended if the patient is able to take small amounts of fluids. Continuous pain in the semiconscious patient might be associated with grimacing and facial tension. However, do not confuse pain with the restlessness, agitation, moaning, and groaning that accompany terminal delirium' [43] (pp. 338339).

Increasing restlessness and agitation can occur in the last days of life due to decreasing organ function as many natural human metabolism products and drugs and their metabolites accumulate in the body. The poor hepatic, renal and pulmonary function all contribute to symptoms and patients and families should be warned that restlessness is a reflection of the last steps of a patient on his/her way [44] (p. 31).

\subsection{Ethical Dilemmas}

The value of an animal's life compared to human life is different for people with different moral values, for example vegetarians argue that we have no right to eat animals. Whereas some owners may request euthanasia of a healthy animal which cannot talk and defend its position. This is the most important ethical dilemma facing veterinarians, which they have to deal with, much as doctors have to consider available options at the end of the lives of their patients.

Arguments against euthanasia in humans are mainly based on morals and ethics, so it is interesting to review the training that vets receive in ethics and end of life issues, preparing them for their duties in caring for animals at the end of their lives [7].

Could it be that the training of medics in ethics needs to be updated due to advancements in medical science? Are they over prescribing opioids and deep sedation during the last weeks of life to cover up suffering? 'A number of intolerable and intractable symptom burdens can occur during the end of life period that may require the use of palliative sedation' [45].

In 2012 a study investigated the ethical knowledge and attitudes of a representative sample of 192 Bavarian physicians with regard to end-of-life decisions, euthanasia, and the physician-patient relationship. It found that the physicians' knowledge of medical ethics was inadequate [46].

\subsection{Personal Concerns}


As a vet I am concerned for the welfare of animals, near the end of their lives, whose owners are led to believe by the current situation in human medicine in the UK that dying naturally is normal and a certain amount of suffering is acceptable.

Physical pain is, I wish I could say 'reputably', but in truth, 'arguably' addressed at the end of life in human medicine but often ignored or not detected in those animals dying 'naturally' at home.

'Modern medicine has made protracted death far more likely than before, and I think we vets rightly become accustomed to only seeing and expecting a swift and painless end. A GP friend called me recently to discuss euthanasia of their dying old dog and so I packed my bag to go. However, a few minutes later she called back to say that she and her husband (also a medic), had decided to allow 'things to happen naturally'. And so they did, and it took a couple of days... I was mortified, but then realised that this was what they were used to seeing and they saw nothing wrong' [47] Butterworth, J. (3rd Dec 2016).

I, and some other vets [47] are extremely concerned about the welfare standards in humans near the end of their lives. Most of these patients are horribly aware of the degradation of life and terrified of further slow deterioration, eventually leading to the dying process with unpredictable pain and suffering. Is it ethically correct to keep a human alive if they are terminally unable/unwilling to eat and/or drink, repeatedly requesting assistance to die and/or their condition is rapidly progressing towards death with suffering obvious to doctors and carers? Is the over use of sedatives and opiates in these cases inadequate and inhumane?

\section{Recommendations}

The Dutch Government took the bull by the horns in 1990, by requesting the first of a series of comprehensive, nationwide, research articles into euthanasia and other medical decisions concerning the end of life [48]. It is time for the British Government to urgently instigate a study of the need for PAS, in the whole of the UK, for the terminally ill, already on palliative care and whose life has become unbearable to them, including those with advanced dementia and advanced neurodegenerative diseases who have a valid 'advance directive' which clearly describes the stage at which they would like assistance to die. It would be useful to include the veterinary profession's views in such a study, as they are medically trained, of the highest integrity and ethical standards and experienced in euthanasia. This study should also include the experiences and views of the public, around the time of the deaths of their close relatives and friends.

The results may reveal the need for a new Draft Bill about assisted dying to be drawn up for consultation so that an acceptable Bill can be presented to Parliament.

Should euthanasia be an end of life option in human medicine in the UK?

\section{Conclusions}

- End of life options in human medicine are highly dependent on where in the world you live.

- Euthanasia of the terminal patient can be a humane option if ending the life of the patient will prevent additional suffering and unnecessary pain.

- A protracted death, even under palliative care, causes unnecessary physical and emotional suffering for the patient and carers. 
- By including euthanasia in end of life options in veterinary medicine there has been considerable relief of suffering for both the patient and owners.

- Quality of life and the welfare of all patients, both human and animal, should be a priority and should not be compromised.

- There are still animals suffering at the end of their lives because of the human precedent of a natural death.

- Some treatments are futile for some patients. If PAS is not an option this leaves only palliative care which may not alleviate refractory symptoms.

- Moral and ethical factors are complex in end of life issues in both veterinary and human medicine. However, due to their training and broad experience veterinarians appear to take a more holistic approach to end of life issues than doctors, in particular with regard to assessing quality of life. Those with such knowledge should be encouraged to come forward to share their expertise in the debate about euthanasia for humans.

- In some cases the UK public think that they are being treated worse than animals because UK citizens do not have the option of euthanasia at the end of their lives.

- The majority of the British public want a change in the Law, approving the option of PAS for the terminally ill.

- The Royal College of Nursing have taken a neutral stance in relation to assisted dying for people who have a terminal illness.

- It is time for the British Government to instigate a comprehensive study, examining the urgent need for the option of euthanasia for those terminally ill, whose quality of life has become unacceptable to them.

Acknowledgments: This article has no source of funding. I would like to thank Malcolm Buchanan, Shelagh-Mary Calvert, Prof Roy McClelland and Paul Vanden Berghe for their comments on previous drafts of this article and Clare Boulton for helping with the search strategy.

Author Contributions: The primary author Ruth Eyre-Pugh conceived this topic and instigated the literature searches, followed the exclusion/ inclusion criteria to arrive at the relevant papers and drafted the initial manuscript. James Yeates designed the separation of the manuscript into two papers, revised the format and conclusions of the papers and advised about preparation for publication.

Conflicts of Interest: 'The authors declare no conflicts of interest.'

\section{References}

1. Brewer, C.; Irwin, M. Eds. 'I'll see Myself Out, Thank You': Thirty personal views in support of assisted suicide; Skyscraper Publications Ltd: Warwickshire, UK, 2015.

2. Parliament of Victoria Legislative Council Legal and Social Issues Committee. Inquiry into end of life choices, Final Report, Victorian Government Printer: Victoria, Australia, 2016; p. xvii. ISBN 9781925458398 Available online: https://www.parliament.vic.gov.au/file_uploads/LSIC_pF3XBb2L.pdf (accessed on 29th July 2017). 
3. Biggs, H. Euthanasia and End-of-Life decision making. In Medicolegal Essentials in Healthcare, 2nd ed.; Payne-James, J., Dean, P., Wall, I., Eds; Greenwich Medical Media: Cambridge, UK, 2004; p 142.

https://books.google.co.uk/books?hl=en\&lr=\&id=iVYqFOINtAC\&oi=fnd\&pg=PA139\&dq=euthanasia+AND+\%22end+of+life\%22\&ots=LhHV9TwHnt\&sig=UfwTz 3DEr14xV4QWbzt0C9FieEM\#v=onepage\&q=euthanasia $\% 20$ AND $\% 20 \% 22$ end $\% 20 \mathrm{of} \% 20 \mathrm{life} \% 22 \& \mathrm{f}=$ false

4. My Death - My Decision, Polls. Available online: https://www.mydeath-mydecision.org.uk/info/polls/ (accessed on 31st January 2017).

5. BMA Physician-assisted dying. Available online: https://www.bma.org.uk/advice/employment/ethics/ethics-a-to-z/physician-assisted-dying (accessed on 20th Feb 2017).

6. Marris, R. House of Commons, Friday 11 September 2015. Available online: https://www.publications.parliament.uk/pa/cm201516/cmhansrd/cm150911/debtext/1509110001.htm\#15091126000003 (accessed on 23rd Feb 2017).

7. Eyre-Pugh, R.E.; Yeates, J.W. Treatment, Palliative Care or Euthanasia? Comparing End of Life Issues in Human and Veterinary Medicine. Preprints 2017, 2017080084 (doi: 10.20944/preprints201708.0084.v1).

8. McPherson, K. (University of Oxford, Oxford, UK). Personal communication, 2017.

9. Bachelard, S. On Euthanasia: Blindspots in the Argument from Mercy. J.Appl.Philos. 2002, 19, 131-140, doi: 10.1111/1468-5930.00210. Available online: http://onlinelibrary.wiley.com/doi/10.1111/1468-5930.00210/full (accessed on 29th May 2017).

10. Karnik, S.; Kanekar, A. Ethical Issues Surrounding End-of-Life Care: A Narrative Review. Healthcare 2016, 4, 24, 1-6, doi: 10.3390/healthcare4020024. Available from: http://dx.doi.org/10.3390/healthcare4020024 (accessed on 13 ${ }^{\text {th }}$ March 2017).

11. Thorns, A. Ethical and legal issues in end-of-life care. Clin. Med. 2010, 10, 282-285, doi: 10.7861/clinmedicine.10-3-282. Available online: http://www.clinmed.rcpjournal.org/content/10/3/282 (accessed on 13th March 2017).

12. Winzelberg, G.; Hanson, L.; Tulsky, J. Beyond autonomy: Diversifying end-of-life decision-making approaches to serve patients and families. J. Am. Geriatr. Soc. 2005, 53, 1046-1050, DOI: 10.1111/j.15325415.2005.53317.x. Available online: http://onlinelibrary.wiley.com/doi/10.1111/j.15325415.2005.53317.x/abstract;jsessionid=7FF1856298FB7B01D4DF7479146A67A5.f02t03

13. Christiansen, S.B.; Kristensen, A.T.; Lassen, J.; Sandoe, P. Veterinarians' role in clients' decision-making regarding seriously ill companion animal patients. Acta Veterinaria Scandinavica 2016, 58, 30, DOI: 10.1186/s13028-016-0211-x. Available online: https://actavetscand.biomedcentral.com/articles/10.1186/s13028-016-0211-x $\quad$ (accessed on 12 ${ }^{\text {th }}$ March 2017).

14. Fiester, A.; Mann, L. Ethical considerations in treating the horse with laminitis. Clinical Techniques in Equine Practice 2004, 3, 103-107, doi: 10.1053/j.ctep.2004.07.011. Available from RCVS Library (accessed on $27^{\text {th }}$ Feb 2017).

15. Platt, B.; Hawton, K.; Simkin, S.; Mellanby, R.J. Systematic Review of the Prevalence of Suicide in Veterinary Surgeons. Occupational Medicine 2010, 60, 436-446, doi:10.1093/occmed/kqq044. Available online: https://oup.silverchaircdn.com/oup/backfile/Content_public/Journal/occmed/60/6/10.1093/occmed/kqq044/2/kqq044.pdf?Expire

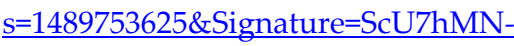

7fEDMVbkfj9AwliyM6okoCg1P 4SLqfvWD0upDjm09Ljutjij0vOvHsX6nVYq1XHBvNNN4yu0Hzs vhiP CrODJKCkcb d-KFuDxbf2-

Tl2oal QAyTueKgH4h4P7JKVur88x2bsmzvnS3ftJHJdxf0m4flNWAKkE67acY9XiUw0p8CEjASg1BHumf hNbci7lcCzh5-RzjFsNjwk1zqOSNkzmc19WmyJoxM9YlKppxsIPiSSULycj1Ks3YH3Hk0invpuIcwDQBBva FNWYAMm5TfdO2BvDIa5WGNk8vTSOuB51tLaHDPrRDM bKheN68xrnSHKgaf0NeA \&Key-Pair-Id=APKAIUCZBIA4LVPAVW3Q (accessed on $13^{\text {th }}$ March 2017).

16. Stark. C.; Dougall. N. Effect of attitudes to euthanasia on vets' suicide risk. Veterinary Record 2012, 171, 172-173, doi: 10.1136/vr.e5494. Available from RCVS Library (accessed on 27 ${ }^{\text {th }}$ Feb 2017).

17. Ogden. U.; Kinnuison. T.; May. S.A. Attitudes to animal euthanasia do not correlate with acceptance of human euthanasia or suicide. Veterinary Record 2012, 171, 174. Available from RCVS Library (accessed on 27th $F e b$ 2017). 
18. Langner, T.S. Choices for Living; Kluwer Academic/Plenum Publishers: New York, USA, 2002; pp. 1-308; ISBN 0-306-46607-4.

19. Zilboorg, G. Fear of Death. Psychoanal. Quart. 1943, 12, 465-475. Available online: http://psycnet.apa.org/psycinfo/1944-01169-001

20. Jong, J.; Ross, R.; Philip, T.; Chang, S.; Simons, N.; Halberstadt, J. The religious correlates of death anxiety: a systematic review and meta-analysis. Religion, Brain $\mathcal{E}$ Behavior 2017, 7, 1-17, doi: 10.1080/2153599X.2016.1238844. Available online: http://www.tandfonline.com/doi/full/10.1080/2153599X.2016.1238844 (accessed on 24th April 2017).

21. Afzali, M.A. Brain death from the perspective of Shia and modern medicine. J Mazandaran Univ Med Sci 2014, 24, 216-220, Available online: http://jmums.mazums.ac.ir/article-1-3808-en.html (accessed on 11th March 2017).

22. James, F.; Bresnahan, S.J. Observations on the Rejection of Physician-Assisted Suicide: A Roman Catholic Perspective, Christian bioethics: Non-Ecumenical Studies in Medical Morality 1995, 1, Issue 3, $256-$ 284, Available online: https://doi.org/10.1093/cb/1.3.256

23. Edney, A.T.B. Breaking the news: The problems and some answers. In Euthanasia of the companion animal; Kay, W.J., Cohen, S.P., Nieburg H.A., Eds.; The Charles Press: Philadelphia, USA, 1988; pp. 181-185.

24. Dickinson, G.E.; Roof, P.D.; Roof, K.W. End-of-Life Issues in United States Veterinary Medicine Schools. Society and Animals 2010, 18, 152-162, DOI: 10.1163/156853010X492006. Available online:

http://www.animalsandsociety.org/wp-content/uploads/2016/04/dickinson.pdf (accessed on 12th March 2017).

25. Pochard, F.; Azoulay, E.; Chevret, S.; Lemaire, F.; Hubert, P.; Canoui, P.; Grassin, M.; Zittoun, R.; le Gall, J.R.; Dhainaut, J.F.; Schlemmer, B. Symptoms of anxiety and depression in family members of intensive care unit patients: ethical hypothesis regarding decision-making capacity. Crit Care Med. 2001, 10, 18931897. Available online:

http://journals.lww.com/ccmjournal/Abstract/2001/10000/Symptoms_of_anxiety_and_depression_in_fami ly.7.aspx.

26. Emanuel, L.; Scandrett, K. Decisions at the end of life: Have we come of age? BMC Med. 2010, 8: 57, 1-8, DOI: 10.1186/1741-7015-8-57. Available online:

http://bmcmedicine.biomedcentral.com/articles/10.1186/1741-7015-8-57 (accessed on 12th March 2017).

27. Weisman, A.D. Bereavement and companion animals. Omega - Journal of Death and Dying 1991, 22, 241248, doi: 10.2190/C54Y-UGMH-QGR4-CWTL. Available online: http://journals.sagepub.com/doi/abs/10.2190/C54Y-UGMH-QGR4-CWTL .

28. Yeates, J.W. Ethical aspects of euthanasia of owned animals. In Practice 2010, 32, 70-73. Available from RCVS Library (accessed on $27^{\text {th }}$ Feb 2017).

29. Landry, J.T.; Foreman, T.; Kekewich, M. Ethical considerations in the regulation of euthanasia and physician-assisted death in Canada. Health Policy 2015, 119, 1490-1498,

DOI: http://dx.doi.org/10.1016/j.healthpol.2015.10.002. http://www.healthpolicyirnl.com/article/S01688510(15)00253-5/fulltext (accessed on 13th March 2017).

30. Folger, B.; Addleman, R.; Rodan, I.; Thayer, V. End of life issues in feline medicine. The Journal of Feline Medicine and Surgery, CLINICAL PRACTICE 2012, 421, 421-422. Available online:

http://www.catvets.com/public/PDFs/PositionStatements/End-of-life-issuescropped.pdf (accessed on 8th March 2017).

31. Nieberg, H.A.; Fischer, A. Pet loss: A thoughtful guide for adults and children; Harper \& Row: New York, USA, 1982.

32. Follmi, J.; Steiger, A.; Walzer, C.; Robert, N.; Geissbuhler, U.; Doherr, M.G.; Wenker, C. A scoring system to evaluate physical condition and quality of life in geriatric zoo mammals. Animal Welfare 2007, 16, 309318, ISSN 0962-7286 Available from RCVS Library (accessed on 27 $7^{\text {th }}$ Feb 2017).

33. Maltoni, M.; Scarpi, E.; Rosati, M.; Derni, S.; Fabbri, L.; Martini, F.; Amadori, D.; Nanni, O. Palliative Sedation in End-of-Life Care and Survival: A Systematic Review. Journal of Clinical Oncology 2012, 30, 1378-1383, DOI: 10.1200/JCO.2011.37.3795. Available online: http://ascopubs.org/doi/pdf/10.1200/ICO.2011.37.3795 (accessed on 9th March 2017)

34. Beller, E.M.; van Driel, M.L.; McGregor, L.; Truong, S.; Mitchell, G. Palliative pharmacological sedation for terminally ill adults. Cochrane Database of Systematic Reviews 2015, 1, 1-41, 
DOI:10.1002/14651858.CD010206.pub2 Available from: https://espace.library.uq.edu.au/view/UQ:381526 (accessed on $9^{\text {th }}$ March 2017).

35. Leboul, D.; Aubry, R.; Peter, J-M.; Royer, V.; Richar, J-F.; Guirimand, F. Palliative sedation challenging the professional competency of health care providers and staff: a qualitative focus group and personal written narrative study. BMC Palliative Care 2017, 16:25, 1-12, DOI: 10.1186/s12904-017-0198-8. Available online: https://bmcpalliatcare.biomedcentral.com/articles/10.1186/s12904-017-0198-8 (accessed on 15th April 2017).

36. General Medical Council, (2013) Duties of a doctor. Available online: http://www.gmcuk.org/guidance/good medical practice/duties of a doctor.asp (accessed on 10th Feb 2017).

37. RCVS Guide to professional conduct: 2017. RCVS: London, UK, 2017. Available online: http://www.rcvs.org.uk/advice-and-guidance/code-of-professional-conduct-for-veterinary-surgeons/pdf/ (accessed on $13^{\text {th }}$ Feb 2017).

38. MacLeod, R.D._On reflection: doctors learning to care for people who are dying. Soc Sci Med. 2001, 52, 1719-1727, doi.org/10.1016/S0277-9536(00)00289-6 Available online: http://www.sciencedirect.com/science/article/pii/S0277953600002896

39. Meier, D.E.; Emmons, C.-A.; Wallenstein, S.; Quill, T.; Morrison, R.S.; Cassel, C.K. A National Survey of Physician-Assisted Suicide and Euthanasia in the United States 1998. New England Journal of Medicine 1998, 338, 1193-1201, DOI: 10.1056/NEJM199804233381706 http://www.nejm.org/doi/full/10.1056/NEJM199804233381706\#t=article (accessed on $8^{\text {th }}$ March 2017).

40. Rollin, B.E. Euthanasia, moral stress, and chronic illness in veterinary medicine. Veterinary Clinics of North America: Small Animal Practice 2011, 41, 651-659, DOI: http://dx.doi.org/10.1016/j.cvsm.2011.03.005.

Available online: http://www.sciencedirect.com/science/article/pii/S0195561611000301

41. BMA End-of-life care and physician-assisted dying: Reflections and Recommendations. BMA: London, UK, 2016; Volume 3, Available online: https://www.bma.org.uk/collective-voice/policy-and-research/ethics/end-oflife-care (accessed on 11th March 2017).

42. wikivet.net Feline Cognitive Dysfunction, reviewed by Bowen, J. 2014. Available online: https://en.wikivet.net/Feline Cognitive Dysfunction (accessed on 14th Feb 2017).

43. Arcand, M. End-of-life issues in advanced dementia. Part 2: Management of poor nutritional intake, dehydration, and pneumonia. Canadian Family Physician 2015, 61, 337-341, Available online: http://www.cfp.ca/content/61/4/337.full (accessed on 11 ${ }^{\text {th }}$ March 2017).

44. Rolke, R. Terminal Restlessness. In: EAPC 2013 13 th world congress of EAPC: Abstracts. Prague Congress Centre, 30 $0^{\text {th }}$ May-2 ${ }^{\text {nd }}$ June 2013. London: HMC, p. 31.

45. Hahn, M.P. Review of palliative sedation and its distinction from euthanasia and lethal injection. J Pain Palliat Care Pharmacother 2012, 26, 30-39, doi: 10.3109/15360288.2011.650353. Available online: http://www.tandfonline.com/doi/full/10.3109/15360288.2011.650353?scroll=top\&needAccess=true

46. Wandrowski, J.; Schuster, T.; Strube, W.; Steger, F. Medical ethical knowledge and moral attitudes among physicians in Bavaria. Dtsch Arztebl Int. 2012, 109, 141-147, doi: 10.3238/arztebl.2012.0141. Available online:

https://www.researchgate.net/profile/Wolfgang Strube/publication/221704052 Medical Ethical Knowled ge and Moral Attitudes Among Physicians in Bavaria/links/56f1546b08ae5c367d4aa2f6.pdf (accessed on 4th Feb 2017).

47. Vetsurgeon.org Forum: Medically Assisted Dying, 29 November 2016. Available to vets online: https://www.vetsurgeon.org/uk/general/f/66/t/25133.aspx (accessed 31st January 2017).

48. Van der Maas, P.J.; van der Wal, G.; Haverkate, I.; de Graaff, C.L.M.; Kester, J.G.C.; Onwuteaka-Philipsen, B.D.; van der Heide, A.; Bosma, J.M.; Willems, D.L. Euthanasia, Physician-Assisted Suicide, and Other Medical Practices Involving the End of Life in the Netherlands, 1990-1995. New England Journal of Medicine 1996, 335, 1699-1705, DOI: 10.1056/NEJM199611283352227. Available online: http://www.nejm.org/doi/full/10.1056/NEJM199611283352227\#t=article (accessed on $13^{\text {th }}$ March 2017). 